International Journal of Engineering \& Technology, 7 (3.11) (2018) 187-192
International Journal of Engineering \& Technology
SPC
Website: www.sciencepubco.com/index.php/IJET
Research paper

\title{
Socio-Environmental Factors and Tuberculosis: an Exploratory Spatial Analysis in Peninsular Malaysia
}

\author{
Abdul Rauf Abdul Rasam ${ }^{1 *}$, Noresah Mohd Shariff ${ }^{2}$, Jiloris F Dony ${ }^{3}$ Alamah Misni $^{1}$ \\ ${ }^{I}$ Faculty of Architecture, Planning and Surveying, Universiti Teknologi MARA, Selangor Malaysia \\ ${ }^{2}$ Geography Programme, School of Distance Education, Universiti Sains Malaysia \\ ${ }^{3}$ Sabah State Health Department, Ministry of Health, Malaysia. \\ *Corresponding author E-mail: rauf@salam.uitm.edu.my
}

\begin{abstract}
Spatial pattern of tuberculosis (TB) describes the environmental variation of the disease. Controlling the disease is not only depends on bio-medical method, but there is also a need to explicitly understand socio-environmental contexts which include the elements of people, space and time. A spatial exploration of local TB dynamic in Malaysia's perspectives is necessary since earlier studies were limited in addressing these contexts. This paper discusses a general spatial pattern of TB distribution pattern in Peninsular Malaysia for a ten-year period from 2005 to 2014 and its general possible correlation with socio-environmental factors in 2010. Geographical information system (GIS) and correlation analysis are fundamental techniques used to explore the local pattern of TB distribution and the relationship. Data on annual TB cases and state map were collected from the Ministry of Health and the Department of Rural and Country Planning Malaysia respectively. The overall spatial pattern of TB cases has shown increasing trends and concentrating in five states, including Selangor, Johor, WPKL, Kelantan and Kedah, even though there is no specific pattern in the area. This study suggests that the majority of the cases have occurred in the urban states, having high-medium incomes and populous areas.
\end{abstract}

Keywords: GIS Correlation; Peninsular Malaysia; Social Environment.; Spatial Pattern;Tuberculosis

\section{Introduction}

This TB occurs in every part of the world and can kill three million people in the world for both of developed or developing countries. [8] reported the majority of the TB cases come from the 22 high burden countries, especially from African and Asian regions. Malaysia recorded medium burden cases of TB incidence with 81 per $10,000,24,711$ cases, and 1,603 deaths in 2004, but the number of new TB cases increased from 15,000 in 2005 to 19,251 in 2011 (MOH, 2012). These local situations and dynamics bring up key research question: which states have the highest cases of TB? and why are the states experienced such risk situations?

Previous studies have shown the environmental risk factors in high burden countries of TB can be divided into two main indicators, including ecological environment, human or social environment. The ecological environment is another term of the environment, relating the biotic and abiotic surrounding of an organism or population, For example, TB high-risk prevalence areas are co-impacted by spatial proximity or geographical factor [1][2][12] especially in urban area [1][12][3][38], poor housing quality, crowded and small living condition [14]. Low SES also contributes to the global TB occurrences [2][12] such as unemployment, low educational level and poverty. Human factors both individual and population have been also identified as a major of global TB epidemics, especially in crowded or higher population, migrant population, high risk group or people with coinfection or infectious disease such as HIV, drugs abuse, AIDS and so on.
Therefore, molecular and analytical epidemiology used to control the disease in terms of local demographic characteristics, genetic, behaviours, environmental exposures, and other potential risk factors. However, there is a need of a geographically based tool for a better understanding of the TB epidemiology (Murray and Alland, 2002; Narayanan, 2004). Studying spatial pattern of TB in Malaysia is imperative to understand well the spatial distribution of the disease since there are limited studies on these particular local perspectives A spatial analysis framework developed by [37] is general guidelines used to control disease in medical and geographical perspective by identifying a spatial pattern and of disease cluster, as well as to predict disease risk factors and areas. This analysis can stimulate an idea to create a hypothetical framework for the dynamics TB distribution pattern and risk factors complexities in the context of Malaysia

\section{Review on Socio-Spatial Relations in the Tuberculosis Environment}

\subsection{Geographical Pattern of Tuberculosis Distribution}

Tuberculosis (TB) is caused by tuberculosis bacilli called as mycobacterium tuberculosis that is spread from person to person through the air, and then it can transmit through a community across the geographical boundaries. TB Epidemiology is a study of the disease distribution and determinants of risk factor in a specified population, and to the control of health problems that related with time, place, and person characteristics. Narayanan, (2004) has suggested apart of human-based tool, there is a need of 
the geographically based tool for a better understanding and controlling of tuberculosis cases.

TB remains a major global health problem that can attack any people or regions both in developed or developing countries. [7] described global TB incidence and estimates that approximately one-third of the global community is infected with M. tuberculosis. $\mathrm{TB}$ is the second most common cause of death due to an infectious disease after human immunodeficiency virus HIV/AIDS. In 2013, the majority of the TB cases come from African and Asian regions especially in South Africa and India [8], where the largest number of new TB cases occurred in the South-East Asia and Western Pacific Regions, accounting for $56 \%$ of new cases globally.

In Malaysia, the TB among high risk groups continue to be an important disease [18]. The number of new TB cases in the country increased from 15,000 in 2005 to 19,251 in 2011 especially in three states of Sabah, Selangor and Sarawak. While pulmonary TB is the commonest form of TB in Malaysia, extrapulmonary TB (EPTB) still posed a threat. The majority of patients are in the 21 60 years age group $(69.5 \%)$ and there is a male predominance (65\%). Overall, most of the global TB cases occur in Asian and African regions, especially in developing countries. In Malaysia, the clustering is dynamically cases since every state has owned risk factors and potentials to be attacked by the TB cases.

\subsection{Tuberculosis in Socio-Spatial Dimensions}

Empirical global studies have shown the common environmental (endogenous or extrinsic) risk factor affects TB risk vulnerability are the biophysical or ecological environment, socioeconomic status, human population and demographic characteristic. TB spatial clustering and variation, the high-risk areas are coimpacted by areal proximity or geographical factor [1][2][12] especially in urban area [1][2][3], and socio-economic status [2][3].

Moreover, human factor both population or individual have been also identified as a major of global TB epidemics including crowded or higher population [4][38], migrant population, high risk group and people with co-infection or another infectious disease such as HIV, drugs abuse, AIDS and so on. Since each country has unique local environments, then the effect of risk factors and dynamics of TB occurrences are might be different in particular areas. As a result, some experts have pointed out some recommendations on these particular problems, as well as to enhance the current result.

The well-established risk factors need to combine among themselves or other potential intrinsic risk factors for major impact on the state of public health in the current century [10] and better reflect the true risk factors of TB burden and guide national TB programmes to execute more effective TB control interventions. Moreover, there a need to be studied in depth in future research for complex relationships such as between SES and environment [1][13][15][33][11][12][16][10][17] .

In the context of Malaysia, The [12] identified the risk of TB transmission came from a high risk group. This human or demographic factor may the main factor affecting local TB occurrences such as pulmonary TB (PTB), patients are in the $21-60$ years age group and male predominanc [12]. Table 1 summarises the common risk factors according to global situations, focusing on social economic status, human population and demographic. It can be concluded that in order to determine potential key risk factors of TB in certain local areas, studying spatial pattern and precise causal associations between TB cases and related risk conditions is crucial to investigate the real scenario of local TB cases.
Table 1: Common Risk Factors in Global Tuberculosis

\begin{tabular}{|c|c|c|}
\hline $\begin{array}{c}\text { Risk } \\
\text { Factor }\end{array}$ & $\begin{array}{l}\text { Specific crite- } \\
\text { ria/determinants }\end{array}$ & $\begin{array}{c}\text { Author }(\mathbf{s}), \\
\operatorname{region}(\mathbf{s})\end{array}$ \\
\hline $\begin{array}{l}\text { 1. Socio Eco- } \\
\text { nomic Status, } \\
\text { SES (Job, sala- } \\
\text { ry and occupa- } \\
\text { tional-related to } \\
\text { poor and social } \\
\text { vulnerability) }\end{array}$ & $\begin{array}{l}\text { 1.1 The level of } \\
\text { education of people } \\
\text { with primary level or } \\
\text { with illiterate level, } \\
\text { type of TB and place } \\
\text { of residence } \\
\text { 1.2. Habi- } \\
\text { tat/settlement cen- } \\
\text { suses, and living } \\
\text { conditions ins linked } \\
\text { 1.3. TB is } \\
\text { with SES environ- } \\
\text { mental factors such } \\
\text { as living condition } \\
\text { and ecological condi- } \\
\text { tion especially in } \\
\text { urban area in } \\
\text { 1.4. Linked to both } \\
\text { the quality of health } \\
\text { care and socio- } \\
\text { economic status. } \\
\text { Confirmation of TB } \\
\text { cluster areas may } \\
\text { help public health } \\
\text { authorities to set up } \\
\text { priorities regarding } \\
\text { to be targeted for } \\
\text { prevention or control } \\
\text { measures } \\
\text { 1.5. Effects of social } \\
\text { vulnerability on the } \\
\text { disease, complex } \\
\text { relationships may } \\
\text { exist between TB } \\
\text { incidence and a wide } \\
\text { range of environ- } \\
\text { mental and intrinsic } \\
\text { factors, which need } \\
\text { to be studied in depth } \\
\text { in future research } \\
\text { 1.6. TB situations are } \\
\text { related with in } \\
\text { neighbourhoods of } \\
\text { low SES }\end{array}$ & $\begin{array}{l}\text { 1.1 [19], West Azerbaijan } \\
\text { Province, Iran. } \\
\text { 1.2. [19][20][22][21] } \\
\text { 1.3. } \\
{[1][12][13][10][13][33][15][1} \\
6] \\
\text { 1.4. [2] Antananarivo, Mada- } \\
\text { gascar. } \\
\text { 1.5 [11], Brazil. } \\
\text { 1.6.[23][24] Cameroon and } \\
\text { Southern Africa. }\end{array}$ \\
\hline $\begin{array}{l}2 \text { Population } \\
\text { and Demo- } \\
\text { graphic Char- } \\
\text { acteristics } \\
\text { (crowd- } \\
\text { ed/density } \\
\text { environment, } \\
\text { migration and } \\
\text { low SES }\end{array}$ & $\begin{array}{l}\text { 2.1 Geographical } \\
\text { characteristics of the } \\
\text { area at the risk are } \\
\text { high density/ popu- } \\
\text { lated areas in the } \\
\text { urban and rural are- } \\
\text { as, poor sanitation, } \\
\text { poorly built housing, } \\
\text { and lack of both } \\
\text { adequate sewage } \\
\text { systems and water } \\
\text { supply facilitate } \\
\text { pathogen spread. } \\
\text { These situations are } \\
\text { related with in } \\
\text { neighbourhoods of } \\
\text { low SES and } \\
\text { HIV/TB mortality } \\
\text { among children aged } \\
\text { 1-5 years } \\
\text { 2.2 TB related with } \\
\text { socio-economic } \\
\text { status specially pov- } \\
\text { erty, urbanicity and } \\
\text { population density in } \\
\text { comparison with } \\
\text { rural areas, but the } \\
\text { higher level of } \\
\text { CS/location, risk } \\
\text { factor/biological and } \\
\text { comparative studies } \\
\text { need to be consid- } \\
\text { ered. }\end{array}$ & $\begin{array}{l}\mathbf{2 . 1}[12][10][13][33][15][16] \text {, } \\
\text { African Region. } \\
\mathbf{2 . 2} \\
{[27[28[29][30][31] \text { American }} \\
\text { Latin. } \\
\mathbf{2 . 3} \text { [32][33][34][35] } \\
\mathbf{2 . 4} \text { [33], USA. }\end{array}$ \\
\hline
\end{tabular}




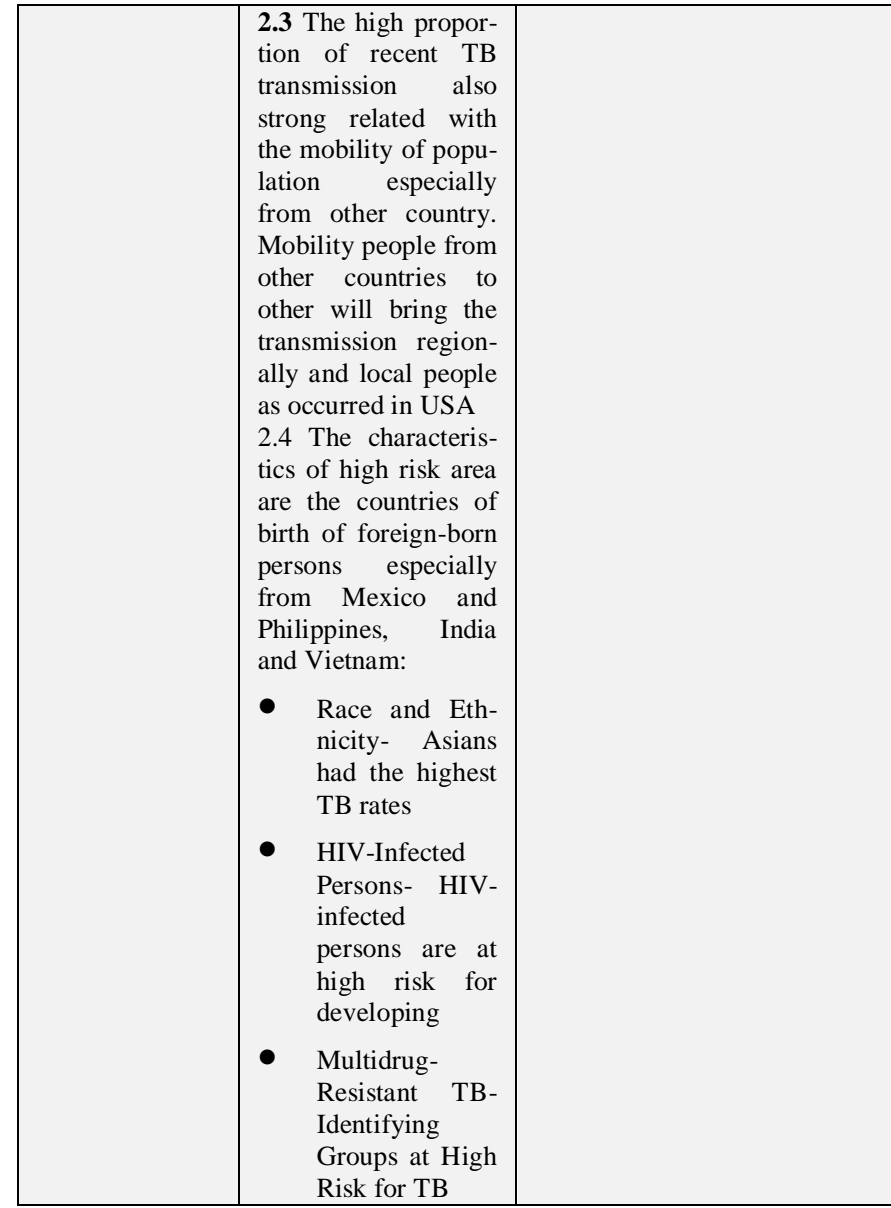

\section{Methodology}

The analytical framework of GIS and spatial epidemiology adapted from [37] is the research methodology used in this study. It includes two main stages, namely, data collection, data processing and data analysis. The first stage describes the study area and datasets used in the study while the second stage covers the process and analysis of the data input of cases and selected variables using classification and Correlation and Spatial Analyst too in ArcGIS. The data analysis describes spatial pattern of TB cases in the Peninsular Malaysia from 2005 to 2014.

\subsection{Study Area and Data Collection}

Peninsular Malaysia or West Malaysia, in Malaysia, is selected as the study area. Malaysia is located in Southeast Asia, with Kuala Lumpur as its capital city (Fig. 1). The Peninsular Malaysia has an area of 8.10 million ha, consisting of twelve administrative states from the smallest area (Perlis), to the largest area (Pahang). The TB cases of state of Wilayah Persekutuan Putrajaya (WPP) are combined into Wilayah Persekutuan Kuala Lumpur (WPKL) because of geopolitical changes. The area as a whole is composed of $80 \%$ present lowland and $20 \%$ highland.

Annual cumulative TB cases from 2005 to 2014 and outline state map of the study area were collected from the TB/Leprosy Sector in Ministry of Health $(\mathrm{MOH})$ and the Department of Town and Country Planning (JBPD), Malaysia. General attributes of the population and urban population (people), monthly income (RM) and non-forested land $\left(\mathrm{km}^{2}\right)$ in 2010 data were acquired from available online sources from the Department of Statistics, Economic Planning Unit (EPU) and Forestry Department in Malaysia. These secondary non-spatial data then were spatially converted and processed into ArcMap and ArcCatalog using a quantitative classification and a correlation coefficient technique.

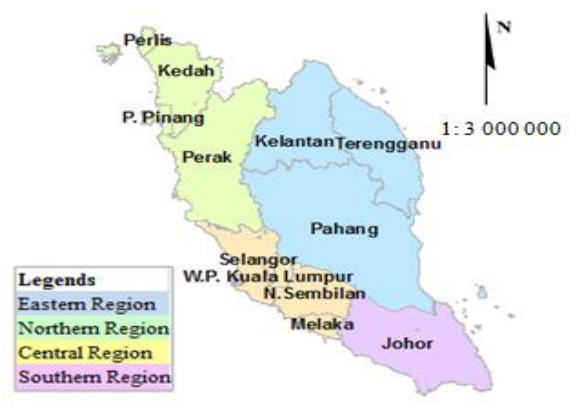

Fig. 1: Map of Peninsular Malaysia, Malaysia.

\subsection{Data Processing, Calculation and Analysis}

The selected data were processed using spatial software or ArcGIS developed by the Environmental System Research Institute (ESRI), especially ArcMap and ArtToolbox tools. The software has some important GIS functions for geocoding, thematic mapping or displaying the data using Malayan Rectified Skew Orthomorphic (MRSO) coordinate systems. Basic GIS operations such as file setup, joining excels spreadsheets with geographic ID fields, and thematically representing data on the maps were conducted in ArcMap and Spatial Analyst tool.

ArcMap is the primary application in ArcGIS and to perform a wide range of common GIS tasks. The mean value of the cumulative TB cases, and the selected variables were used as a scale for determining the risk level of TB occurrences and risk factors in this study. For example, the total TB cases in the study area are 136,864 people and its mean value is 11,405 people after they are divided by 12 (states). If the total of cases in a particular state is more than the mean value, hence the state is assumed as a high risk area (darker colour).

Pearson's correlation coefficient, $r$ is also another statistical technique applied in this study to measure the descriptive pattern, association and strength of the relationship between any two variables such as environmental factors and TB cases (Fig. 2). [36] states if the relationship is weak, then knowing the value of one attribute variable does not predict the value of the second variable.

The value of this correlation is also expressed in terms of a coefficient and it has a range (maximum negative [-1] and positive [+1]). When the correlation coefficient approaches a maximum negative value, it means that there is a strong negative correlation. This means that the higher the value of one attribute variable, the lower the value will be of the other variable (e.g. the lower the monthly income rate, the higher the TB incidence). There are two ways to calculate the correlation, which are based on sample data

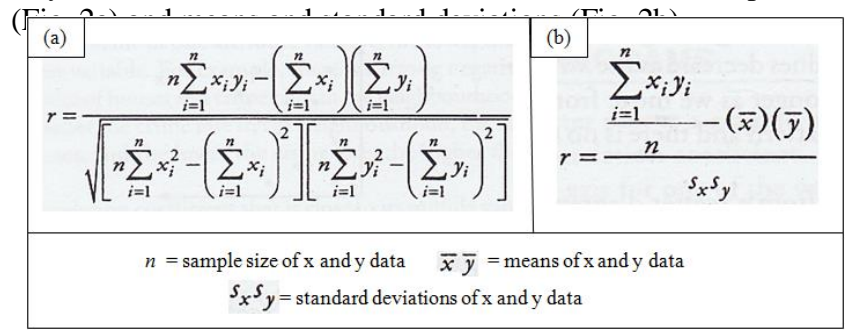

Fig. 2: Calculation of Pearson's correlation coefficient, $r$ [36]

\section{Result and Discussion}

\subsection{Spatial Pattern of Tuberculosis Cases}


Fig. 3 and Fig. 4 show the total cumulative TB cases by states in Peninsular Malaysia for 10 years period from 2005 to 2014. The total number of the cumulative cases recorded for the 10 years were 136, 864 cases, in which Selangor dominated the cases with $21.7 \%$ of the grand total of the cases, followed by Johor (13.7\%), WPKL (11.3\%), Perak (9.8\%), and Kelantan (9.7\%). While, Pulau Pinang, Kedah, Pahang and Terengganu recorded the medium risk of TB cases, started from $7.6 \%$ to $5.1 \%$. The other states that reported the total number of TB cases less than 5,000 cases or 5\% were considered as low risk states, consisting of Negeri Sembilan (3.5\%), Melaka (3.2\%), and Perlis $(0.9 \%)$.

The cases which notified more than the mean value of the total cumulative TB cases or 11,405 cases $(8.3 \%)$ are categorised as an abnormal situation or a high risk state, whilst the others are identified as medium and low risk states. Therefore, the figures also reveal that more than $66.2 \%$ of the overall cases in the area were assumed as high risk states, including Kelantan, Perak, WPKL, Johor, and Selangor. The other states only expressed low and medium risk situations, especially in Pulau Pinang, Kedah, Pahang Terengganu, Negeri Sembilan, Melaka and Perlis.

Referring to the TB time series plot by the states and years in Peninsular Malaysia from 2005 to 2014 (Fig. 5), it is clearly explained that Selangor dominated the total cases by $21.7 \%$. The other states reported constant higher cases than the mean value (1141 cases) were Johor, WPKL, Perak and Kelantan. The rest of the states only showed the medium and low risk of TB cases, particularly in Perlis, Melaka and Negeri Sembilan.

An interesting trend was found in Selangor, Johor, WPKL, Pulau Pinang and Kedah where they have more significant dynamics or variations of cumulative TB distribution compared to the other states. These phenomenal dynamics might be caused by several possible factors, including the local complexities of TB transmission process, or the effectiveness of the particular state health TB control program in the disease detection and treatment.

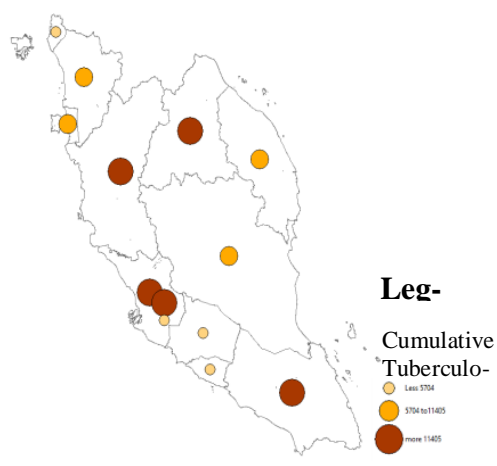

Fig. 3: A spatial pattern of cumulative TB cases in Peninsular

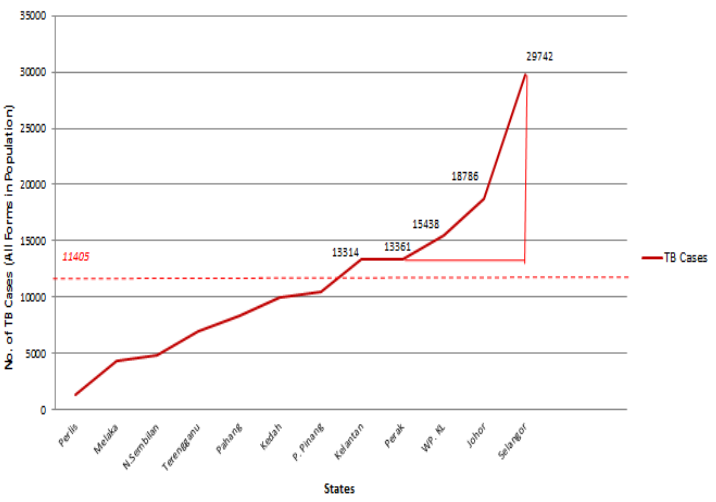

Fig. 4: A Trend of cumulative TB cases in Peninsular Malaysia, 2005-2014

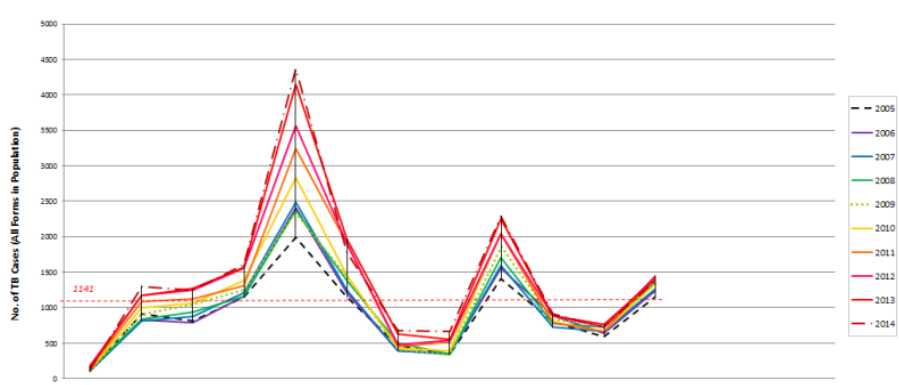

Fig. 5: Trends of TB cases in Peninsular Malaysia from 2005 to 2014

Fig. 6 illustrates the spatial distribution pattern of TB cases in Peninsular Malaysia by states using geographical information system (GIS) technology. Similarly, the cases increased in term of a number of cases and every state had also experienced with TB occurrences. In the early three years of 2005 to 2011, the cases are likely to be significantly increased in some regions of the study area, especially in Selangor, WPKL, Johor, Perak and Kelantan. After that, in 2012 to 2014, the cases spread out to Kedah and P.Pinang then consistently occurred in these states. The state of Perlis, N.Sembilan and Melaka only notified low-medium risk for ten year-cases
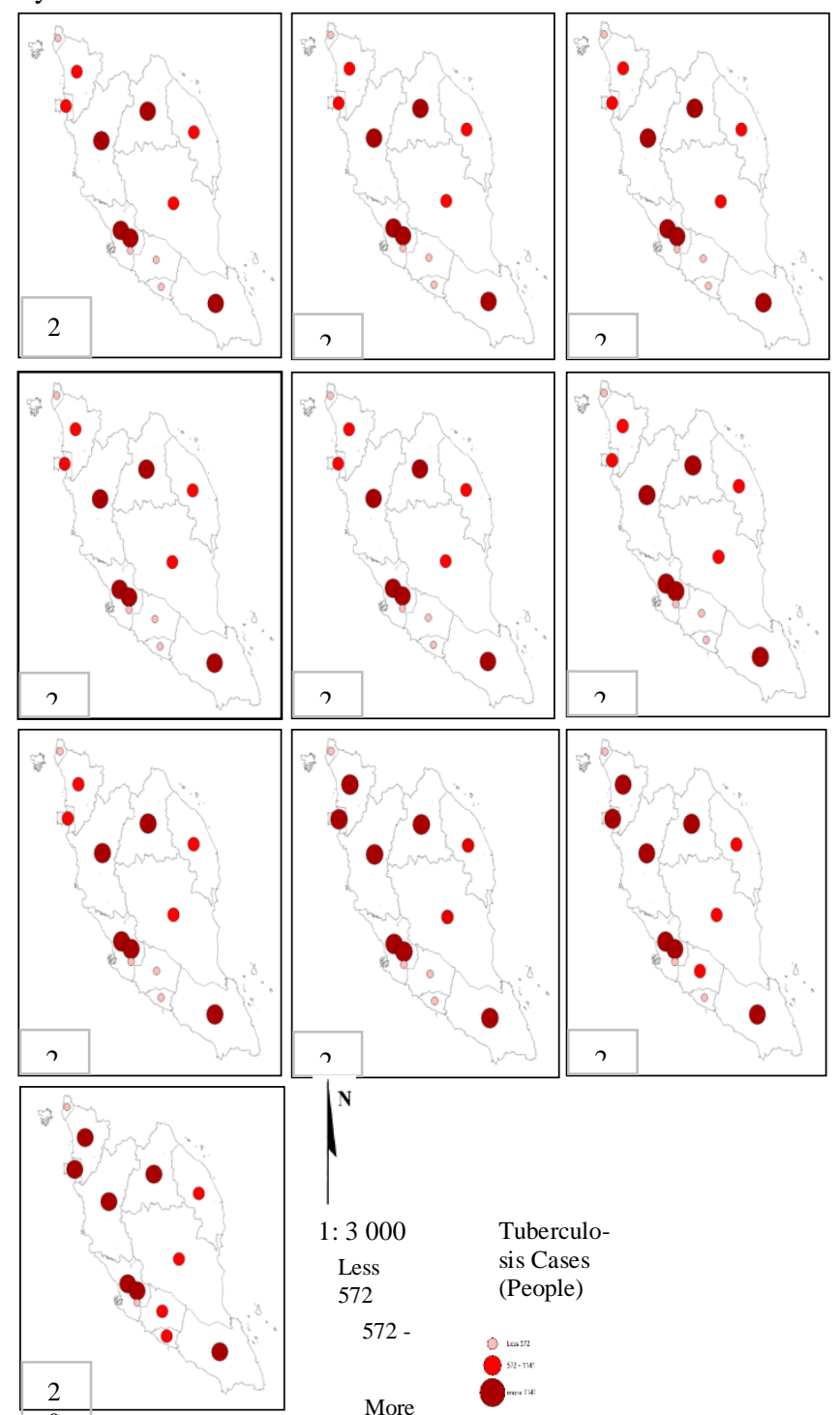

Fig. 6: A spatial distribution pattern of TB cases and risk level in Peninsular Malaysia 
There was no specific clustering found in the study area since the pattern was slightly randomly distributed. The states with high risk situations have similarities in term of the environmental characteristics of TB ecology, particularly in the case of population changes. However, there were some differences in terms of biophysical environments and socioeconomic status (SES) since TB could be occurring either in urban and/or in rural areas even though they are having high urbanisation or better socioeconomic status. For example, Kelantan and Perak are in medium category in term of the socioeconomic status and urbanization, compared to Selangor and WPKL. This result is consistent with finding found from previous studies that geographical characteristics of the area at the risk are high density/ populated areas in the urban and rural areas [10][23][24][25][26].

Table 2: Potential risk states in Peninsular Malaysia

\begin{tabular}{|l|l|l|}
\hline \multicolumn{1}{|c|}{$\begin{array}{c}\text { Risk Level of TB } \\
\text { (Cases) }\end{array}$} & \multicolumn{1}{|c|}{ States } & \multicolumn{1}{|c|}{ Year } \\
\hline Cases & Selangor, Johor, WPKL, Perak & $2005-$ \\
High & Kelantan & 2014 \\
\hline (All Forms) & P. Pinang, Kedah, Pahang, Ter- & $2005-$ \\
Medium & engganu & 2014 \\
\hline & N.Sembilan, Melaka, Perlis, & $2005-$ \\
Low & & 2014 \\
\hline
\end{tabular}

Table 3: Correlation analysis of TB risk factors in Peninsular Malaysia

\begin{tabular}{|l|l|l|}
\hline \multicolumn{1}{|c|}{ TB Clustering } & \multicolumn{1}{|c|}{ Correlation } & Range of Period \\
\hline $\begin{array}{l}\text { Overall TB Cluster- } \\
\text { ing of Cases }\end{array}$ & $\begin{array}{l}\text { No apparent clustering is } \\
\text { detected at this scale (Ran- } \\
\text { dom) }\end{array}$ & $2005-2014$ \\
\hline Correlation (2010) & & \\
\hline $\begin{array}{l}\text { Possible Effect of } \\
\text { Related Environ- } \\
\text { ments on TB Cases }\end{array}$ & $r=0.953$ (Very Strong) & 2010 \\
\hline $\begin{array}{l}\text { TB Cases Vs No. of } \\
\text { Population }\end{array}$ & $\begin{array}{l}\text { TB Cases Vs Mean } \\
\text { Monthly Household } \\
\text { Income }\end{array}$ & $r=0.578$ (Moderate) \\
\hline $\begin{array}{l}\text { TB Cases Vs Urban } \\
\text { Population }\end{array}$ & $r=0.403$ (Weak) & 2010 \\
\hline $\begin{array}{l}\text { TB Cases Vs Non } \\
\text { Forested Land }\end{array}$ & $r=-0.134$ (Very Weak) & 2010 \\
\hline
\end{tabular}

\subsection{Spatial Correlation between Tuberculosis Cases and Socio-Environmental Factors}

The results of the trendlines of TB in Fig. 7 revealed the cases in Peninsular Malaysia seemed to potentially occur at anywhere and any local environments, especially in urban and populous areas of human socioeconomic or recreational concentration. For example, Selangor, Johor and WPKL are located in urban areas and have high income states, where their Mean Monthly Gross Household Income (EPU, 2015) are more than the mean value of the overall monthly income of the study area in 2010 , showing human factor has a significant effect on TB cases in the states. Statistically, correlation analysis also found that TB cases in 2010 were significantly correlated with the number of population and mean monthly income $(r>0.500)$ rather than urban population and nonforested land $(r<0.500)$ (Figure 22). This correlation exposed the impact of local risk of of the popula-

ion and social economic status could be higher than biophysical environments on the TB occurrences.

\subsection{Spatial characterisation and correlation of potential risk tb states in Peninsular Malaysia}

Table 2 and Table 3 highlight the key findings in this study, comprising three main level of TB risk describing the TB spatial pattern from 2005 to 2014. Obviously, result from the GIS and spatial epidemiological techniques have demonstrated the spatial distribution pattern of TB cases in Peninsular Malaysia was randomly distributed since there were no clear qualitative clustering have been detected. But the state of Selangor, Johor and WPKL were still the top states in recording the highest cases. These dynamics of TB occurrences can lead to the local complexities in determining explicit risk factors, causing the cases could occur at any place and biophysical environments in Peninsular Malaysia especially in Selangor, WPKL, Johor, Melaka and Pulau Pinang.

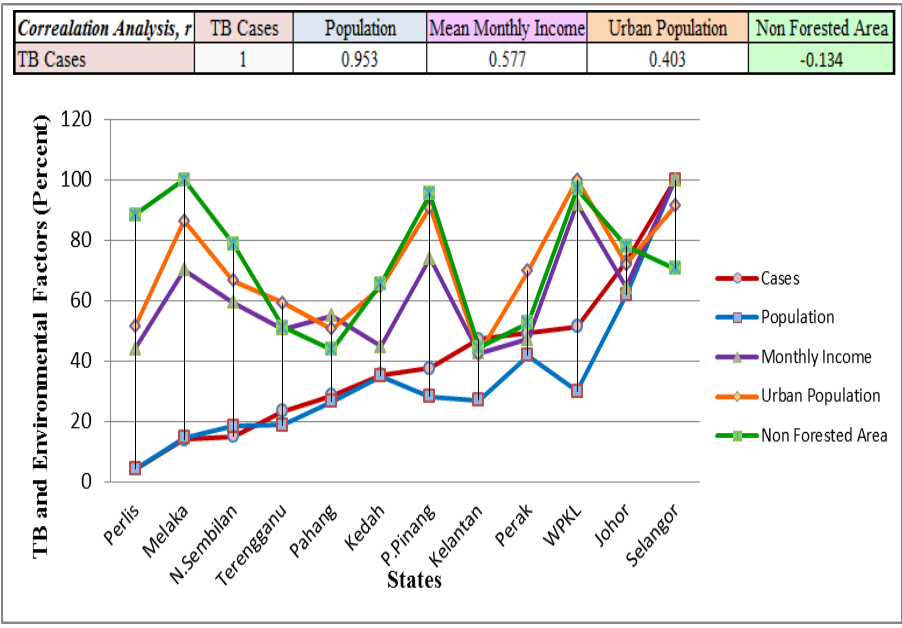

Fig. 7: Correlations between TB cases and selected risk factors in Peninsu-

\section{Conclusion}

An explicit understanding on the TB distribution pattern is a fundamental process to explore an initial idea of the local transmission of diseases, the possible relationship with related environmental risk factors, and identifying potentially high risk areas. The integration of geographical information system (GIS) and spatial visualisation techniques have demonstrated their analytical capabilities for exploring geographic dynamics of tuberculosis (TB) cases and incidences in Peninsular Malaysia from 2005 to 2014. In general, the TB distribution in the area seems to be in dynamic pattern and risk factors are also complex since the local clustering of the disease is not detected explicitly. The spatial pattern for the ten years TB cases shows an increasing trend, particularly in Selangor, Johor, and WPKL, but no definite clustering are determined in these states. Overall, an interesting hypothesis that could be further investigated is that why the majority of the cases occurred in the urbanised states such as Selangor, WPKL, and Johor, with high-medium incomes and populous areas. The findings are not only to answer the local TB dynamics and characterisation of high risk areas in general spatial perspective, but also provide a spatial knowledge for local researchers and decision makers to find, detect, and treat better solutions to the national TB strategies and challenges. Additional data on the risk factors and other spatial regression techniques can be further explored for more significant results.

\section{Acknowledgement}

The researchers are grateful to the TB and Leprosy Sector in Ministry of Health Malaysia, the Town and Country Planning Department, Department of Statistics, Fishery Department and Economic Planning Malaysia in providing the secondary data of the study. This study has been registered in the National Medical Research Register, Malaysia (ID: NMR R -15-2499-24207). The paper is sponsored by Perdana Bestari Grant, UiTM Selangor Malaysia.

\section{References}

[1] J. Yazdani-Charati, H. Siamian, A. Kazemnejad, and V. Mohammad, "Spatial clustering of tuberculosis incidence in the north of iran.," Glob. J. Health Sci., vol. 6, no. 6, p. 37130, Jun. 2014.

[2] T. Wang, F. Xue, Y. Chen, Y. Ma, and Y. Liu, "The spatial 
epidemiology of tuberculosis in Linyi," BMC Public Health, vol. 12, p. $885,2012$.

[3] W. Tian-Yong, Z. Qing, L. S. Wei, Z. Han, Y. Juan, LiQin, and X. $\mathrm{Yu}$, "ds Analysis of spatial distribution and influencing factors of tuberculosis in Chongqing from 2008 to 2011.pdf," J. Shanghai Jiantong Univ., vol. 33, no. 4, p. 489, 2013.

[4] D. W. Wardani, L. Lazuardi, Y. Mahendradhata, and H. Kusnanto, "Clustered tuberculosis incidence in Bandar Lampung, Indonesia Dyah," WHO South-East Asia J. Public Heal., vol. 3, no. 2, pp. 179-185, 2014.

[5] M. Murray and D. Alland, "Methodological Problems in the Molecular Epidemiology of Tuberculosis," Am. J. Epidemiol., vol. 155 , no. 6 , pp. $565-571,2002$.

[6] S. Narayanan, "Molecular epidemiology of tuberculosis," Indian J Med Res, no. October, pp. 233-247, 2004.

[7] B. Mathema, N. E. Kurepina, P. J. Bifani, and B. N. Kreiswirth, "Molecular epidemiology of tuberculosis: current insights.," Clin. Microbiol. Rev., vol. 19, no. 4, pp. 658-85, Oct. 2006.

[8] W. H. O. WHO, "Tuberculosis," 2015. [Online]. Available: http://www.who.int/mediacentre/factsheets/fs104/en.

[9] M. Malaysia Ministry of Health, A. Academy of Medicine Malaysia, and M. Malaysian Thoracic Society, "Management of TB, 3rd Edition," Malaysia Health Technology Assessment Section (MaHTAS) Medical Development Division, Ministry of Health Malaysia, 2012.

[10] J. R. Oppong, J. Mayer, and E. Oren, "The global health threat of African urban slums: the example of urban tuberculosis," African Geogr. Rev., no. December, pp. 1-14, Apr. 2014.

[11] D. Leite, C. Gullaci, and E. Z. Martinez, "Major Article Spatiotemporal patterns of tuberculosis incidence in Ribeirão Preto , State of São Paulo , southeast Brazil , and their relationship with social vulnerability : a Bayesian analysis," Rev. Soc. Bras. Med. Trop., vol. 45 , no. 5, pp. $607-615,2012$

[12] Y. Liu, X. Li, W. Wang, Z. Li, M. Hou, Y. He, W. Wu, H. Wang, H. Liang, and $\mathrm{X}$. Guo, "Investigation of space-time clusters and geospatial hot spots for the occurrence of tuberculosis in Beijing," INT J TUBERC LUNG DIS, vol. 16, no. 4, pp. 486-491, 2012.

[13] M. E. F. Brunello, F. C. Neto, R. A. Arcêncio, R. L. de P. Andrade, G. T. Magnabosco, and T. C. S. Villa, "Areas of vulnerability to HIV / TB co-infection in Southeastern," Rev Saúde Pública, vol. 45, no. 3, 2011.

[14] M. L. Feske, L. D. Teeter, J. M. Musser, and E. a Graviss, "Including the third dimension: a spatial analysis of TB cases in Houston Harris County.," Tuberculosis (Edinb)., vol. 91 Suppl 1, pp. S24-33, Dec. 2011

[15] M. W. Borgdorff and D. Van Soolingen, "The re-emergence of tuberculosis: what have we learnt from molecular epidemiology?," Clin. Microbiol. Infect., vol. 19, no. 10, pp. 889-901, Oct. 2013.

[16] C.-T. Low, P.-C. Lai, W.-S. C. Tse, C.-K. Tsui, H. Lee, and P.-K. Hui, "Exploring tuberculosis by types of housing development.," Soc. Sci. Med., vol. 87, no. 2013, pp. 77-83, Jun. 2013.

[17] K. R. M. Rao, Y. Kant, K. Yadav, and S. Chandra, "Disease modeling - An alert system for informing environmental risk factor for TB infection," J. Biomed. Eng. Med. Imaging, vol. 1, no. 1, 2004.

[18] MOH, Ministry of Health Malaysia, "GUIDELINE FOR PREVENTION \& MANAGEMENT OF TUBERCULOSIS FOR HEALTH CARE WORKERS IN MINISTRY OF HEALTH," Putrajaya, 2012.

[19] A. R. Foroushani, F. Farzianpour, and A. Tavana, "The 10-year Trend of TB Rate in West Azerbaijan Province, Iran from 2001 to 2010," Iran. J Publ Heal., vol. 43, no. 6, pp. 778-786, 2014.

[20] R. V Randremanana, V. Richard, F. Rakotomanana, P. Sabatier, and D. J. Bicout, "Bayesian mapping of pulmonary tuberculosis in Antananarivo, Madagascar.," BMC Infect. Dis., vol. 10, p. 21, Jan. 2010.

[21] E. Oren, M. Narita, C. Nolan, and J. Mayer, "Neighborhood socioeconomic position and tuberculosis transmission: a retrospective cohort study.," BMC Infect. Dis., vol. 14, no. 1, p. 227, Jan. 2014.

[22] A. Nolasco, J. A. Quesada, J. Moncho, I. Melchor, P. PereyraZamora, N. Tamayo-Fonseca, M. A. Martínez-Beneito, and O. Zurriaga, "Trends in socioeconomic inequalities in amenable mortality in urban areas of Spanish cities, 1996-2007.," BMC Public Health, vol. 14, p. 299, Jan. 2014.

[23] A. N. Yakam, J. Noeske, P. Dambach, S. Bowong, and L. A. Fono, "Spatial analysis of tuberculosis in Douala, Cameroon : clustering and links with socio-economic status," Int. J. Tuberc. Lung Dis., vol. 18, no. 3, pp. 292-297, 2014.

[24] E. Musenge, P. Vounatsou, M. Collinson, S. Tollman, and K. Kahn,
"The contribution of spatial analysis to understanding HIV/TB mortality in children: a structural equation modelling approach," Glob Health Action 2013, vol. 19266, no. 1, 2013.

[25] K. Touray, I. M. Adetifa, a Jallow, J. Rigby, D. Jeffries, Y. B. Cheung, S. Donkor, R. a Adegbola, and P. C. Hill, "Spatial analysis of tuberculosis in an urban west African setting: is there evidence of clustering?," Trop. Med. Int. Health, vol. 15, no. 6, pp. 664-72, Jun. 2010.

[26] S. D. Hamusse, M. Demissie, and B. Lindtjørn, "Trends in TB case notification over fifteen years: the case notification of 25 Districts of Arsi Zone of Oromia Regional State, Central Ethiopia.," BMC Public Health, vol. 14, p. 304, Jan. 2014.

[27] C. Erazo, S. M. Pereira, M. da C. N. Costa, D. Evangelista-Filho, J. U. Braga, and M. L. Barreto, "Tuberculosis and living conditions in Salvador, Brazil : a spatial analysis," Rev Panam Salud Publica, vol. 2008, no. 1, pp. 24-30, 2014

[28] G. Harling and M. C. Castro, "A spatial analysis of social and economic determinants of tuberculosis in Brazil.," Health Place, vol. 25, pp. 56-67, Jan. 2014.

[29] E. L. N. Maciel, W. Pan, R. Dietze, R. L. Peres, S. A. Vinhas, F. K. Ribeiro, M. Palaci, R. R. Rodrigues, E. Zandonade, and J. E. Golub, "Spatial patterns of pulmonary tuberculosis incidence and their relationship to socio-economic status in Vitoria, Brazil," Int $J$ Tuberc Lung Dis, vol. 14, no. 11, pp. 1395-1402, 2013.

[30] R. P. F. de Queiroga, L. D. de Sá, J. de A. Nogueira, E. R. V. de Lima, P. G. O. D. Pinheiro, A. C. O. Silva, and J. U. Braga, "Spatial distribution of tuberculosis and relationship with living conditions in an urban area of Campina Grande - 2004 to 2007 Distribuição espacial da tuberculose e a relação com condições de vida," Rev Bras Epidemio, vol. 15, no. 1, pp. 222-232, 2012.

[31] A. Zaragoza Bastida, M. Hernández Tellez, L. P. Bustamante Montes, I. Medina Torres, J. N. Jaramillo Paniagua, G. D. Mendoza Martínez, and N. Ramírez Durán, "Spatial and temporal distribution of tuberculosis in the State of Mexico, Mexico.," Sci. World J., vol. 2012, p. 570278, Jan. 2012.

[32] E. Nava-Aguilera, Y. López-Vidal, E. Harris, A. Morales-Pérez, S. Mitchell, M. Flores-Moreno, A. Villegas-Arrizón, J. LegorretaSoberanis, R. Ledogar, and N. Andersson, "Clustering of Mycobacterium tuberculosis cases in Acapulco: Spoligotyping and risk factors.," Clin. Dev. Immunol., vol. 2011, p. 408375, Jan. 2011.

[33] M. Lynn Feske, "Endemic Tuberculosis, the Homeless, and Public Transportation: A Merging of Geographical Information Systems Surveillance and the Houston Tuberculosis Initiative Surveillance Project," The University of Texas, 2011.

[34] C. Prussing, C. Castillo-Salgado, N. Baruch, and W. A. Cronin, "Geo-Epidemiologic and Molecular Characterization to Identify Social , Cultural , and Economic Factors Where Targeted Tuberculosis Control Activities Can Reduce Incidence in Maryland $2004-2010, " 2013$.

[35] L. Couceiro, P. Santana, and C. Nunes, "Pulmonary tuberculosis and risk factors in Portugal :," INT J TUBERC LUNG DIS, vol. 15, no. May 2010, pp. 1445-1454, 2011.

[36] T. Buyong, Spatial statistics for geographic information science. Penerbit UTM, Skudai, Johor Bahru. pp. 983-52, 0393-8 (3). 2006.

[37] P. Dirk, "Epidemiological Spatial Analysis of Animal Health Problems". 2008

[38] A.R.Abdul Rasam, N.M. Shariff, and Dony, J. F, "Ïdentifying High-Risk Populations of Tuberculosis Using Environmental Factors and GIS Based Multi-Criteria Decision Making Method" ISPRS - International Archives of the Photogrammetry, Remote Sensing and Spatial Information Sciences, XLII-4/W1, Pp 9-13. doi:10.5194/isprs-archives-XLII-4-W1-9-2016. 2016. 